\title{
Digestibilidade e desempenho em cordeiros alimentados com dietas contendo feno de amoreira
}

\author{
Digestibility and performance of lambs fed with diets containing \\ mulberry hay
}

\author{
Luís Gabriel Alves Cirne ${ }^{1 *}$; Américo Garcia da Silva Sobrinho²; \\ Valéria Teixeira Santana ${ }^{3}$; Felipi Ulian Silva ${ }^{3}$; Emanuel Almeida de Oliveira²; \\ Fabiana Alves de Almeida ${ }^{3}$; Viviane Endo ${ }^{3}$; Roque Takahashi'; \\ Gleidson Giordano Pinto de Carvalho ${ }^{4}$; Nivea Maria Brancacci Lopes Zeola ${ }^{5}$
}

\section{Resumo}

O experimento foi conduzido com objetivo de avaliar o consumo, a digestibilidade e o desempenho em cordeiros alimentados com dietas contendo $0 ; 12,5$ e 25\% de feno de amoreira em substituição ao concentrado. Foram utilizados 24 cordeiros Ile de France, não-castrados, com aproximadamente 60 dias de idade e peso corporal inicial de $15 \mathrm{~kg}$, confinados, distribuídos num delineamento experimental inteiramente casualizado. O consumo voluntário de nutrientes não foi alterado $(\mathrm{P}>0,05)$ pelos diferentes teores de inclusão de feno de amoreira no concentrado, com exceção do extrato etéreo que apresentou redução linear $(\mathrm{P}<0,01)$. A digestibilidade dos nutrientes, os dias de confinamento, o ganho de peso diário e a conversão alimentar também não foram afetados $(\mathrm{P}>0,05)$. A substituição parcial do concentrado, à base de farelo de soja e milho em grão moído, pelo feno de amoreira em até $25 \%$ não compromete o consumo, a digestibilidade dos nutrientes e o desempenho de cordeiros em confinamento.

Palavras-chave: Alimento alternativo, confinamento, consumo, ganho de peso

\begin{abstract}
The experiment was conducted to evaluate the intake, the digestibility and the performance of lambs fed with diets containing $0 ; 12,5$ and $25 \%$ of mulberry hay in substitution of the concentrate. It was used a total of 24 lambs Ile de France breed, non castrated, average age 60 days and and $15 \mathrm{~kg}$ of body weight, confined, distributed in a completely randomized design. Voluntary intake of nutrients was not altered $(\mathrm{P}>0.05)$ by different percentages of mulberry hay inclusion in the concentrate, except ether extract which decreased linear $(\mathrm{P}<0.01)$. The digestibility of nutrients, days on feeding, daily weight gain and the feed conversion, were also not affected $(\mathrm{P}>0.05)$. The partial substitution of the concentrate, based on soybean meal and corn grain, by mulberry hay up to $25 \%$ does not compromise the intake, the digestibility of nutrients and the performance of diet of feedlot lambs.
\end{abstract}

Key words: Alternative feed, feedlot, intake, weight gain

${ }^{1}$ Prof. e Pesquisador, Universidade Federal de Roraima, UFRR, Boa Vista, RR. E-mail: lgabrielcirne@hotmail.com

${ }^{2}$ Profs. e Pesquisadores, Universidade Estadual Paulista, UNESP, Jaboticabal, SP. E-mail: americo@fcav.unesp.br; moroto. oliveira@hotmail.com; takahashi@fcav.unesp.br

${ }^{3}$ Discentes, UNESP, Jaboticabal, SP. E-mail: santana_vt@yahoo.com.br; slow_dr@yahoo.com.br; endo_vica@hotmail.com; faalvesalmeida@yahoo.com.br

${ }^{4}$ Prof. e Pesquisador, Universidade Federal da Bahia, UFBA, Salvador, BA. E-mail: gleidsongiordano@yahoo.com.br

${ }^{5}$ Pesquisadora, UNESP, Jaboticabal, SP. E-mail: nivea.brancacci@ig.com.br

* Autor para correspondência 


\section{Introdução}

A deficiência nutricional nas diferentes fases do processo produtivo é um dos obstáculos ao desenvolvimento da produção ovina no Brasil. Assim, são válidos todos os esforços de pesquisas na área de alimentação animal para elevação dos índices de produção e produtividade dos rebanhos. A terminação de cordeiros em confinamento tem apresentado balanço econômico desfavorável em relação aos custos de insumos, principalmente os concentrados proteicos. Nesse sentido, fontes proteicas alternativas têm sido utilizadas como opção aos alimentos tradicionais (YAMAMOTO et al., 2007).

A amoreira (Morus sp.) pertence à família Moraceae (TAKAHASHI, 1988), e sua utilização como forrageira, na alimentação ovina, é devido às suas características agrostológicas como adaptação a diferentes solos e climas, fácil propagação vegetativa, capacidade de rebrota, sistema radicular pivotante, com numerosas raízes secundárias e terciárias, que permitem um bom crescimento vegetativo mesmo em períodos secos do ano (FONSECA; FONSECA, 1986), produção de massa verde de 25 a $30 \mathrm{t} / \mathrm{ha} / \mathrm{ano}$, teor de proteína bruta de 18 a 28\% (BA; GIANG; NGOAN, 2005), nutrientes digestíveis totais de 76\% (BAMIKOLE et al., 2005), boa aceitabilidade (SANCHEZ, 2002) e digestibilidade da matéria seca de 75 a $85 \%$ (BA; GIANG; NGOAN, 2005), que caracterizam esta planta como importante alternativa alimentar (TAKAHASHI, 1988).

Alguns trabalhos na literatura avaliaram $\mathrm{o}$ uso da amoreira no desempenho de ruminantes (LIU et al., 2001; SILVA, 2006; OKAMOTO et al., 2008), entretanto pesquisas avaliando o efeito da substituição da proteína do farelo de soja pela proteína da amoreira, na alimentação de ovinos, são escassas. Carregal e Takahashi (1983), ao compararem o valor nutritivo dos fenos de amoreira e de soja perene (Glicyne wightii) na alimentação de coelhos em crescimento, observaram diferenças
$(\mathrm{P}<0,05)$ nos coeficientes de digestibilidade, com valores de 66,0 e $49,9 \%$ para MS; 43,8 e 31,3\% para fibra bruta e 72,9 e 50,2\% para os carboidratos não-fibrosos, respectivamente; para $\mathrm{PB}$ não foi constatada diferença, sendo esta de 75,7\%. Os autores concluíram que o valor nutritivo do feno de amoreira foi superior ao do feno de soja perene. Nageswara, Nawab e Ogra (1996), ao avaliarem duas dietas com teores proteicos semelhantes na alimentação de caprinos, ambas com $40 \%$ de folhas secas de amoreira ou de neem (Azadirachta indica), concluíram que, com exceção do extrato etéreo, a digestibilidade dos demais nutrientes foi maior para o feno de amoreira. Liu et al. (2001), ao estudarem a substituição total do farelo de canola (Brassica napus) por folhas de amoreira no desempenho de ovinos, concluíram que as folhas de amoreira podem substituir o farelo de canola.

Neste sentido, objetivou-se avaliar o consumo, a digestibilidade e o desempenho em cordeiros, alimentados com dietas contendo feno de amoreira.

\section{Material e Métodos}

O experimento foi desenvolvido no Setor de Ovinocultura do Departamento de Zootecnia da Faculdade de Ciências Agrárias e Veterinárias, FCAV - Unesp, Campus de Jaboticabal, SP, utilizando-se 24 cordeiros da raça Ile de France, não castrados, recém-desmamados e com $15 \mathrm{~kg}$ de peso corporal médio.

Os animais foram alojados em baias individuais, com aproximadamente $1,0 \mathrm{~m}^{2}$, com piso ripado e suspenso, equipadas com comedouro e bebedouro individuais e instaladas em galpão coberto. No início do experimento, os cordeiros foram identificados, submetidos ao controle de ectoparasitos, imunizados com vacina polivalente contra clostridioses, suplementados com vitaminas A, D e E por via intramuscular e distribuídos por sorteio nos tratamentos.

As dietas experimentais (Tabela 2) foram 
calculadas para atender às exigências preconizadas pelo NRC (2007) para cordeiros desmamados, com ganho de peso médio diário de $300 \mathrm{~g} / \mathrm{animal} /$ dia. A relação volumoso:concentrado das dietas (D) foi 50:50, sendo os tratamentos constituídos pelas porcentagens de substituição do concentrado por feno de amoreira em: zero de substituição e/ ou ausência do feno de amoreira (testemunha), 12,5 e $25 \%$ de substituição do concentrado pelo feno de amoreira. A cana-de-açúcar utilizada como volumoso foi a variedade forrageira IAC 86-2480 picada em tamanho de partículas de 1,0 $\mathrm{cm}$ e fornecida in natura. As ramas de amoreira, provenientes da Sirgaria do Setor de Sericicultura da FCAV- Unesp, foram cortadas com 90 dias de rebrota (BA; GIANG; NGOAN, 2005) e altura média de 2,0 $\mathrm{m}$. Das ramas foram retiradas as folhas (pecíolo e limbo) e a parte apical da planta que, posteriormente, foram desidratadas ao sol até atingirem o ponto de feno com $15 \%$ de umidade (CAVAlCANTE et al., 2004). Após fenado, esse material foi moído utilizando-se peneira com malha de $0,8 \mathrm{~mm}$ com o intuito de facilitar a uniformização dos concentrados e evitar a seletividade pelos animais.

A alimentação foi fornecida em duas refeições, sendo $50 \%$ às $7 \mathrm{~h}$ e os outros $50 \%$ às $17 \mathrm{~h}$, de forma a permitir, no mínimo, $10 \%$ de sobras; e diariamente, foi registrado o peso do alimento oferecido e das sobras após o período de adaptação às baias e às dietas de quatorze dias, para determinação do consumo de matéria seca (MS) e da conversão alimentar (CA), obtida pela relação entre o consumo de MS e o ganho de peso diário de todo o período experimental. O consumo de nutrientes foi calculado pela diferença entre a quantidade do nutriente presente nos alimentos fornecidos e a quantidade do nutriente nas sobras, de acordo com a seguinte fórmula: Consumo $(\mathrm{kg})=$ nutriente ingerido - nutriente nas sobras.

Os animais passaram por um período de adaptação às baias e às dietas de 14 dias, após esse momento os mesmos foram pesados no início e final do período experimental após jejum de sólidos de 14 horas e a cada 14 dias para avaliação do ganho de peso e da conversão alimentar, momento no qual foi monitorada também a haemoncose pelo método Famacha ${ }^{\circledR}$ (VAN WYK; BATH, 2002), até atingirem $32 \mathrm{~kg}$ de peso corporal, sendo que o tempo de confinamento foi em função do peso final dos animais. Os animais com ovos por gramas de fezes (OPG) acima do aceitável foram desverminados pela associação levamisol $(0,05 \mathrm{~mL} / \mathrm{kg})+$ albendazol $(0,1 \mathrm{~mL} /$ $\mathrm{kg})$.

Durante o período de confinamento, amostras dos ingredientes (Tabela 1), alimentos fornecidos, das sobras e das fezes foram coletadas e présecas em estufa com circulação de ar forçada a $55^{\circ} \mathrm{C}$, por 72 horas e posteriormente, moídas em moinho tipo Willey com peneira de crivos de um mm para determinação dos teores de MS, matéria orgânica (MO), matéria mineral (MM), extrato etéreo (EE) e energia bruta (EB), conforme metodologias descritas por Silva e Queiroz (2002). O teor de nitrogênio total das amostras foi obtido pelo método de combustão de Dumas, utilizandose analisador LECO FP-528 LC, seguindo o procedimento descrito por Etheridge, Pesti e Foster (1998) e multiplicado por 6,25 para se obter o valor de proteína bruta (PB) total. Os teores de lignina, fibra em detergente neutro corrigida para cinzas e proteína (FDNcp) e fibra em detergente ácido (FDA), foram determinados de acordo com Van Soest (1994) e recomendados pelo fabricante do aparelho ANKOM Technology ${ }^{\circledR}$, utilizando-se sacos de ANKOM. Os carboidratos totais (CHOT) foram calculados pela equação: $\mathrm{CHOT}=100-$ $(\% \mathrm{~PB}+\% \mathrm{EE}+\% \mathrm{MM})$ e os não-fibrosos (CNF), estimados por adaptação à formula proposta por Hall (2000): $\mathrm{CNF}=100-[(\% \mathrm{~PB}-\mathrm{PBu}+\mathrm{U})+$ $\% \mathrm{EE}+\% \mathrm{MM}+\% \mathrm{FDNcp}]$, em que: PBu é o teor de $\mathrm{PB}$ proveniente da ureia $(\%)$ e U é o teor de ureia $(\%)$. 
Tabela 1. Composição químico-bromatológica dos ingredientes das dietas experimentais.

\begin{tabular}{lcccc}
\hline Nutriente & Cana-de-açúcar & Feno de amoreira & Milho grão moído & Farelo de Soja \\
\hline Matéria seca & 27,12 & 89,36 & 89,12 & 89,05 \\
Matéria orgânica $^{1}$ & 97,70 & 89,45 & 97,79 & 92,37 \\
Matéria mineral $^{1}$ & 2,30 & 10,55 & 2,21 & 7,63 \\
Proteína bruta $^{1}$ & 2,92 & 20,92 & 14,26 & 44,28 \\
Extrato etéreo $^{1}$ & 0,38 & 2,64 & 6,75 & 1,74 \\
Lignina $^{1}$ & 2,28 & 2,69 & 1,40 & 2,40 \\
Fibra em detergente neutro $^{1,2}$ & 33,72 & 21,99 & 17,75 & 12,42 \\
Fibra em detergente ácido $^{1}$ & 22,75 & 15,47 & 4,80 & 8,54 \\
Carboidratos totais $^{1}$ & 92,80 & 65,89 & 76,78 & 46,35 \\
Carboidratos não-fibrosos $^{1}$ & 60,56 & 45,38 & 60,51 & 35,41 \\
Energia bruta (Mcal/kg MS) & 4,29 & 4,54 & 4,65 & 4,73 \\
\hline
\end{tabular}

${ }^{1}$ em $\% ;{ }^{2}$ corrigida para cinzas e proteína.

Fonte: Elaboração dos autores.

Tabela 2. Composição percentual dos ingredientes e bromatológica das dietas experimentais.

\begin{tabular}{lccc}
\hline Composição & \multicolumn{3}{c}{ Feno de amoreira (\%) } \\
\cline { 2 - 3 } & 0 & 12,5 & 25 \\
\hline Percentual (\%) & & & 50,00 \\
Cana-de-açúcar & 50,00 & 5,00 & 25,00 \\
Feno de amoreira & - & 12,50 & 21,33 \\
Farelo de soja & 28,49 & 24,60 & 0,00 \\
Milho em grão moído & 17,80 & 9,00 & 1,00 \\
Óleo de soja & 1,00 & 1,00 & 0,80 \\
Ureia & 0,80 & 0,80 & 0,50 \\
Suplemento mineral e vitamínico ${ }^{1}$ & 0,50 & 0,50 & 0,25 \\
Calcário calcítico & 0,47 & 0,43 & 1,12 \\
Fosfato bicálcico & 0,94 & 1,17 & \\
Bromatológica (na MS) & & & 57,18 \\
Matéria seca & 58,44 & 56,94 & 91,92 \\
Matéria orgânica & 93,63 & 92,56 & 5,87 \\
Matéria mineral & 4,17 & 4,99 & 18,40 \\
Proteína bruta & 18,88 & 18,51 & 2,21 \\
Extrato etéreo & 2,88 & 2,55 & 2,32 \\
Lignina & 2,07 & 2,19 & 25,01 \\
Fibra em detergente neutro ${ }^{2}$ & 23,56 & 24,26 & 17,92 \\
Fibra em detergente ácido & 16,54 & 17,20 & 72,76 \\
Carboidratos totais & 73,27 & 72,95 & 51,57 \\
Carboidratos não-fibrosos & 53,57 & 52,74 & 73,58 \\
Nutrientes digestíveis totais (\%) & 79,11 & 76,61 & 2,55 \\
Energia metabolizável (Mcal/kg MS) & 2,99 & 2,95 & \\
\hline
\end{tabular}

'Níveis de garantia por kg do produto: Cálcio $120 \mathrm{~g}$, cloro $90 \mathrm{~g}$, cobalto $10 \mathrm{mg}$, cobre $50 \mathrm{mg}$, enxofre $34 \mathrm{~g}$, ferro $1064 \mathrm{mg}$, fósforo $50 \mathrm{~g}$, iodo $25 \mathrm{mg}$, magnésio $54 \mathrm{~g}$, manganês $1500 \mathrm{mg}$, selênio $20 \mathrm{mg}$, sódio $62 \mathrm{~g}$ e zinco $1600 \mathrm{mg}$, Flúor (Max) 0,73g, vitamina A 100.000 UI, vitamina D3 40.000 UI e vitamina E 600 UI; ${ }^{2}$ corrigida para cinzas e proteína.

Fonte: Elaboração dos autores. 
$\mathrm{O}$ teor de nutrientes digestíveis totais (NDT) foi obtido a partir da equação somativa: NDT $=$ PBD $+2,25 \times \mathrm{EED}+\mathrm{FDNcpD}+\mathrm{CNFD}$, em que PBD, EED, FDNcp e CNFD significam, respectivamente, proteína bruta digestível, extrato etéreo digestível, fibra em detergente neutro (isenta de cinzas e proteína) digestível e carboidratos não-fibrosos digestíveis. A energia metabolizável (EM) foi obtida a partir do ensaio de digestibilidade e da estimativa da produção de gases no rúmen pela fórmula: $\mathrm{EM}=\mathrm{EBi}$ - (EBf + EBu + EPGD), sendo que: EBi é a energia bruta ingerida, EBf é a energia bruta das fezes, EBu é a energia bruta na urina e EPGD é a energia para a produção de gases obtida pela fórmula: EPGD = PGD x EBi/100, sendo PGD $=4,28+0,059 \mathrm{DG}$, em que DG é a digestibilidade da energia em porcentagem (BLAXTER, 1962).

O delineamento experimental foi o inteiramente casualizado com 3 tratamentos e 8 repetições, totalizando 24 unidades experimentais. Os resultados foram avaliados por meio de análises de variância e regressão, com os graus de liberdade desdobrados em efeitos linear ou quadrático, de acordo com as porcentagens de feno de amoreira. A significância das regressões foi obtida pelo teste $\mathrm{F}$ a 1 ou $5 \%$ de probabilidade utilizando-se o programa estatístico Sisvar (FERREIRA, 2000), empregandose o modelo matemático:

$\mathrm{Y}_{\mathrm{ij}}=\mu+\mathrm{T}_{\mathrm{i}}+\mathrm{e}_{\mathrm{ij}}$, sendo:

$\mathrm{Y}_{\mathrm{ij}}=$ valor observado da variável estudada no indivíduo $\mathrm{j}$, recebendo o tratamento $\mathrm{i}$;

$\mu=$ média geral;

$\mathrm{Ti}=$ efeito do tratamento $\mathrm{i}$, variando de 1 a 3 (0; 12,5 e $25 \%$ de inclusão de feno de amoreira no concentrado);

eij = erro aleatório associado a cada observação.

Após 45 dias do início do ensaio de desempenho, foi conduzido o ensaio de digestibilidade, utilizandose 15 dos mesmos animais. Os cordeiros foram alojados em gaiolas de metabolismo individuais, adotando-se sete dias de adaptação e cinco dias de coleta total de fezes, sendo que após o ensaio de digestibilidade os animais retornaram para as baias para continuação do experimento de desempenho. Após 24 horas de cada dia de coleta, as fezes foram colhidas, pesadas e amostradas $(10 \%$ do total excretado), obtendo-se uma amostra composta de cada animal ao final do período. A digestibilidade dos nutrientes foi determinada segundo a equação: digestibilidade $(\%)=$ [nutriente ingerido $(\mathrm{g})$ nutriente excretado nas fezes $(\mathrm{g}) /$ nutriente ingerido $(\mathrm{g})]^{*} 100$.

O delineamento experimental utilizado para o ensaio de digestibilidade foi em blocos casualizados com 3 tratamentos e 5 repetições, totalizando 15 unidades experimentais. Os resultados foram avaliados por meio de análises de variância e regressão, com os graus de liberdade desdobrados em efeitos linear ou quadrático, de acordo com as porcentagens de feno de amoreira. A significância das regressões foi obtida pelo teste $\mathrm{F}$ a 1 ou $5 \%$ de probabilidade utilizando-se o programa estatístico Sisvar (FERREIRA, 2000), empregando-se o modelo matemático:

Yij $=\mu+\mathrm{Ti}+\mathrm{Pj}+\mathrm{eij}$, sendo:

Yij = valor observado da variável estudada no indivíduo $\mathrm{j}$, recebendo o tratamento $\mathrm{i}$;

$\mu=$ média geral;

$\mathrm{Ti}=$ efeito do tratamento $\mathrm{i}$, variando de 1 a 3 $(0 ; 12,5$ e $25 \%$ de inclusão de feno de amoreira no concentrado);

$\mathrm{Pj}=$ Efeito do período $\mathrm{j}(\mathrm{j}=1,2, \ldots, 5)$.

eij = erro aleatório associado a cada observação.

\section{Resultados e Discussão}

O consumo de MS, MO, PB, FDN, FDA, CHOT, CNF e EM (Tabela 3) não foi influenciado $(\mathrm{P}>0,05)$ pela adição de feno de amoreira em substituição parcial ao concentrado à base de farelo de soja e milho em grão moído, na dieta dos cordeiros (Tabela 2), com exceção do EE 
que apresentou redução linear $(\mathrm{P}<0,01)$ à medida que se aumentou as percentagens de inclusão de feno de amoreira. A redução da ingestão de EE atribui-se ao maior teor desse nutriente advindo de ingredientes como o milho, que, continha maior proporção na dieta controle e na que possuía $12,5 \%$ de feno de amoreira (Tabela 2). Possivelmente, a ingestão de nutrientes foi similar entre os tratamentos em função de o consumo de MS ter sido próximo e, também, porque as dietas apresentaram composição químico-bromatológica semelhantes.

Tabela 3. Consumo voluntário de nutrientes ( $\mathrm{kg} /$ dia) e de energia metabolizável (EM) em cordeiros alimentados com dietas contendo diferentes porcentagens de feno de amoreira.

\begin{tabular}{|c|c|c|c|c|c|c|}
\hline \multirow{2}{*}{ Consumo } & \multicolumn{3}{|c|}{ Feno de amoreira (\%) } & \multicolumn{2}{|c|}{ Valor $\mathrm{P}^{1}$} & \multirow{2}{*}{$\mathrm{CV}(\%)^{2}$} \\
\hline & 0 & 12,5 & 25 & $\mathrm{~L}$ & $\mathrm{Q}$ & \\
\hline MS & 1,300 & 1,279 & 1,352 & 0,517 & 0,495 & 9,91 \\
\hline MO & 0,635 & 0,625 & 0,660 & 0,519 & 0,497 & 9,89 \\
\hline PB & 0,245 & 0,236 & 0,248 & 0,821 & 0,414 & 9,95 \\
\hline $\mathrm{EE}$ & 0,037 & 0,032 & 0,028 & 0,000 & 0,845 & 9,36 \\
\hline FDN & 0,306 & 0,310 & 0,338 & 0,113 & 0,472 & 9,90 \\
\hline FDA & 0,215 & 0,220 & 0,242 & 0,061 & 0,468 & 9,96 \\
\hline CHOT & 0,952 & 0,933 & 0,983 & 0,594 & 0,486 & 9,91 \\
\hline $\mathrm{CNF}$ & 0,696 & 0,675 & 0,697 & 0,986 & 0,492 & 9,88 \\
\hline EM (Mcal) & 3,895 & 3,778 & 3,445 & 0,055 & 0,572 & 9,76 \\
\hline \multicolumn{6}{|c|}{ Equação de regressão } & $\mathrm{r}^{2}$ \\
\hline EE & \multicolumn{3}{|c|}{$Y=0,037394-0,000183 x$} & & & 0,99 \\
\hline
\end{tabular}

${ }^{1} \mathrm{P}=$ probabilidade ${ }^{2} \mathrm{CV}=$ coeficiente de variação.

Fonte: Elaboração dos autores.

A ingestão média de MS (1,310 kg) encontrada, neste estudo, foi próxima ao recomendado pelo NRC (2007), que é de 1,250 kg/dia para cordeiros com peso corporal médio de $30 \mathrm{~kg}$, respectivamente. O consumo de MS é importante no desempenho de ovinos em confinamento, pois pode ser considerado determinante do aporte de nutrientes necessários para o atendimento das exigências de mantença e de ganho de peso dos animais (SNIFFEN et al., 1993).

Estes resultados são semelhantes aos observados por Anbarasu et al. (2004), que, ao avaliarem a substituição da proteína do concentrado à base de farelo de soja por uma ração contendo feno de amoreira na dieta de caprinos, não observaram diferença no consumo de nutrientes; e por Carvalho et al. (2006), que, ao estudarem o desempenho e digestibilidade de ovinos da raça Santa Inês alimentados com farelo de cacau (Theobroma cacao
1.) em diferentes porcentagens de substituição pelo concentrado composto de farelo de soja e milho, não registraram alteração no consumo de nutrientes, indicando que o feno de amoreira também seja uma boa fonte proteica alternativa no arraçoamento de ruminantes.

A digestibilidade aparente dos nutrientes não variou ( $\mathrm{P}>0,05)$ em função da substituição do farelo de soja e do milho em grão moído pelo feno de amoreira no concentrado (Tabela 4). Este resultado decorre do fato de as dietas serem isonitrogenadas, com $18,59 \%$ PB e teores de fibra semelhantes (Tabela 2), além da alta degradabilidade da fibra contida no feno de amoreira (MAKKAR; SINGH; NEGI, 1989; SCHMIDEK, 1999), não afetando a digestibilidade dos nutrientes, quando da substituição do farelo de soja e do milho em grão moído pelo feno de amoreira. 
Tabela 4. Digestibilidade dos nutrientes em cordeiros alimentados com dietas contendo diferentes porcentagens de feno de amoreira.

\begin{tabular}{lccccccc}
\hline \multirow{2}{*}{ Digestibilidade (\%) } & \multicolumn{3}{c}{ Feno de amoreira (\%) } & & \multicolumn{2}{c}{ Valor P $^{1}$} & \multirow{2}{*}{ CV (\%) $)^{2}$} \\
\cline { 2 - 3 } & 0 & 12,5 & 25 & & L & Q & \\
MS & 79,10 & 78,66 & 74,24 & & 0,083 & 0,380 & 4,59 \\
MO & 77,28 & 79,65 & 75,58 & & 0,632 & 0,305 & 6,25 \\
PB & 84,25 & 86,47 & 80,07 & & 0,116 & 0,068 & 4,07 \\
EE & 74,41 & 73,76 & 68,39 & & 0,077 & 0,391 & 5,92 \\
FDN & 48,46 & 50,14 & 48,47 & & 0,999 & 0,735 & 15,99 \\
FDA & 42,60 & 47,88 & 38,46 & & 0,608 & 0,304 & 25,63 \\
CHOT & 78,07 & 74,57 & 74,80 & & 0,389 & 0,565 & 6,74 \\
CNF & 94,68 & 90,80 & 92,46 & & 0,419 & 0,254 & 4,00 \\
EB & 78,29 & 75,45 & 69,15 & & 0,068 & 0,661 & 8,43 \\
\hline
\end{tabular}

${ }^{1} \mathrm{P}=$ probabilidade ${ }^{2} \mathrm{CV}=$ coeficiente de variação.

Fonte: Elaboração dos autores.

Resultado semelhante ao do presente estudo foi observado por Doran, Laca e Sainz (2007), que, ao analisarem a digestibilidade dos nutrientes em caprinos arraçoados com dietas à base de feno de aveia e amoreira ou feno de aveia e alfafa, não encontraram influência na digestibilidade dos nutrientes com valores médios de 64,60; 66,60; 76,$40 ; 48,70$ e 46,50\%, respectivamente para a MS, MO, PB, FDN e FDA; por Kandylis, Hadjigeorgiou e Harizanis (2009), que, ao compararem a digestibilidade dos nutrientes em ovinos arraçoados com dietas com e sem feno de amoreira, não verificaram alteração, com exceção do $\mathrm{EE}$, com valores médios de 69,40;71,40; 63,00 e 57,80 para MS, PB, EE e fibra bruta, respectivamente; e aos coeficientes de digestibilidade dos nutrientes registrados por Moreno et al. (2010a), com exceção do FDN e FDA, que obtiveram valores médios de 78,91; 80,17; 81,30; 78,60; 79,89; 93,20 e 78,77\%, respectivamente, para a $\mathrm{MS}, \mathrm{MO}, \mathrm{PB}, \mathrm{EE}, \mathrm{CHOT}$, CNF e EB, o que evidencia o potencial de utilização do feno de amoreira no arraçoamento de cordeiros em confinamento.

Segundo Okamoto et al. (2008), uma das principais características da amoreira como forrageira é a sua alta aceitabilidade e digestibilidade, conferindo-lhe elevado valor energético, além de possuir folhas com altos teores proteicos e minerais, além de baixo teor de fibra em detergente neutro e celulose e maior digestibilidade quando comparada com folha de alfafa ou feno de soja (DORIGAN et al., 2004), os quais são alimentos de alto valor biológico normalmente utilizados na dieta de cordeiros.

Os cordeiros terminados em confinamento alimentados com dietas contendo feno de amoreira apresentaram desempenho semelhante aos do grupo controle (Tabela 5), sendo que o ganho de peso diário, a conversão alimentar e os dias de confinamento não diferiram ( $\mathrm{P}>0,05)$, com médias de $0,253 \mathrm{~kg} / \mathrm{dia}, 3,19$ e 66 dias, respectivamente. A semelhança entre os resultados pode estar relacionada ao fato de os animais terem apresentado o consumo de nutrientes similares (Tabela 3), além da idade, sexo, raça e peso dos animais estudados terem sido equivalentes, o que sugere que o feno de amoreira seja uma fonte proteica alternativa na alimentação de cordeiros em confinamento. 
Tabela 5. Dias de confinamento (DC), ganho de peso diário (GPD) e conversão alimentar (CA) em cordeiros alimentados com dietas contendo diferentes porcentagens de feno de amoreira.

\begin{tabular}{|c|c|c|c|c|c|c|}
\hline \multirow{2}{*}{ Item } & \multicolumn{3}{|c|}{ Feno de amoreira (\%) } & \multicolumn{2}{|c|}{ Valor $\mathrm{P}^{1}$} & \multirow{2}{*}{$\mathrm{CV}(\%)^{2}$} \\
\hline & 0 & 12,5 & 25 & $\mathrm{~L}$ & Q & \\
\hline$\overline{\mathrm{DC}}$ & 64,80 & 66,80 & 66,40 & 0,601 & 0,651 & 7,14 \\
\hline GPD (kg/dia) & 0,257 & 0,249 & 0,254 & 0,732 & 0,455 & 6,05 \\
\hline CA (kg MS/kg PV) & 3,21 & 3,15 & 3,22 & 0,943 & 0,688 & 8,06 \\
\hline
\end{tabular}

${ }^{1} \mathrm{P}=$ probabilidade $;{ }^{2} \mathrm{CV}=$ coeficiente de variação.

Fonte: Elaboração dos autores.

Fontes proteicas alternativas em substituição ao farelo de soja são muito estudadas no intuito de reduzir os custos com alimentação na terminação de cordeiros em confinamento, entretanto pesquisas avaliando o efeito da substituição da proteína do farelo de soja pela proteína da amoreira na alimentação de ovinos são escassas. Miller, Mcdonald e Asiedu (2005) não encontraram diferença no desempenho de cabritos alimentados com inclusão de 50 e $100 \%$ de farelo de feno de amoreira em substituição ao concentrado, concluindo que o concentrado pode ser totalmente substituído pelo farelo de feno de amoreira; da mesma forma, $\mathrm{Vu}$ et al. (2011) não registraram influência no desempenho de tourinhos alimentados com inclusão de 5, 10 e $15 \%$ de folhas de amoreira em substituição ao caroço de algodão no concentrado, concluindo que o caroço de algodão pode ser completamente substituído pelas folhas de amoreira; e Silva (2006) que observou desempenho semelhante em cordeiros da raça Suffolk alimentados com dietas em que o concentrado continha $15 \%$ de feno de amoreira, feno de alfafa, amendoim forrageiro ou aveia no concentrado, indicando que a qualidade nutricional do feno de amoreira na composição do suplemento para cordeiros foi semelhante à dos ingredientes supracitados.

O ganho de peso diário e a conversão alimentar dos cordeiros foram similares aos obtido por Moreno et al. (2010a), de 0,235 kg/dia e 3,13 kg MS/kg PC, respectivamente, em cordeiros da raça IIe de France, em confinamento, alimentados com dietas constituídas de cana-de-açúcar variedade IAC 86-
2480 e concentrado à base de milho em grão moído e farelo de soja, numa relação 60:40, contendo 3,81 Mcal de EM/kg de MS e 19\% de PB; e por Moreno et al. (2010b), de 0,255 kg/dia e 3,27 kg MS/ $\mathrm{kg}$ PC, respectivamente, em cordeiros da raça IIe de France, em confinamento, alimentados com dietas compostas de silagem de milho e concentrado à base de milho em grão moído e farelo de soja, numa relação 40:60, contendo 2,54 Mcal de EM/kg de MS e $18 \%$ de $\mathrm{PB}$, o que demonstra o bom valor nutritivo do feno de amoreira (SANCHEZ, 2002; OKAMOTO et al., 2008; VU et al., 2011).

\section{Conclusão}

O feno de amoreira em até $25 \%$ do concentrado não compromete o consumo, a digestibilidade e o desempenho de cordeiros confinados, podendo o feno de amoreira ser utilizado como boa alternativa alimentar.

\section{Agradecimentos}

A Fundação de Amparo à Pesquisa do Estado de São Paulo (FAPESP) por ter financiado este estudo.

\section{Referências}

ANBARASU, C.; DUTTA, N.; SHARMA, K.; RAWAT, $\mathrm{M}$. Response of goats to partial replacement of dietary protein by a leaf meal mixture containing Leucaena leucocephala, Morus alba and Tectona grandis. Small Ruminant Research, Amsterdam, v. 51, n. 1, p. 47-56, 2004. 
BA, N. X.; GIANG, V. D.; NGOAN, L. D. Ensiling of mulberry foliage (Morus alba) and the nutritive value of mulberry foliage silage for goats in central Vietnam. Livestock Research for Rural Development, Cali, v. 17, n. 2, p. 1-9, 2005.

BAMIKOLE, M. A.; IKHATUA, M. I.; IKHATUA, U. J.; EZENWA, I. V. Nutritive value of mulberry (Morus Spp.) Leaves in the growing rabbits in nigeria. Pakistan Journal of Nutrition, Faisalabad, v. 4, n. 4, p. 231-236, 2005.

BLAXTER, K. L. The energy metabolism of ruminants. London: Hutchinson \& Company, 1962. 329 p.

CARREGAL, R. D.; TAKAHASHI, R. Composição entre o valor nutritivo dos fenos de soja perene (Glycine wrightii verdec) e amoreira (Morus alba L.), através da digestibilidade aparente em coelhos. In: REUNIÃO ANUAL DA SOCIEDADE BRASILEIRA DE ZOOTECNIA, 20., 1983, Pelotas. Anais... Pelotas: Sociedade Brasileira de Zootecnia, 1983. p. 66.

CARVAlHO, G. G. P.; PIRES, A. J. V.; VELOSO, C. M.; DA SILVA, F. F.; SILVA, R. R. Desempenho e digestibilidade de ovinos alimentados com farelo de cacau (Theobroma cacao L.) em diferentes níveis de substituição. Ciência Animal Brasileira, Goiânia, v. 7, n. 2, p. 115-122, 2006.

CAVALCANTE, A. C. R.; PEREIRA, O. G.; VALADARES FILHO, S. C.; RIBEIRO, K. G.; GARCIA, R.; LANA, R. P. Dietas contendo silagem de milho (Zea maiz L.) e feno de capim-Tifton 85 (Cynodon spp.) em diferentes proporções para bovinos. Revista Brasileira de Zootecnia, Viçosa, v. 33, n. 6, p. 2394-2402, 2004.

DORAN, M. P.; LACA E. A.; SAINZ, R. D. Total tract and rumen digestibility of mulberry foliage (Morus alba), alfalfa hay and oat hay in sheep. Animal Feed Science and Technology, Amsterdam, v. 138, n. 3-4, p. 239-253, 2007.

DORIGAN, C. J.; RESENDE, K. T.; BASAGLIA, R.; SUGOHARA, A.; TAKAHASHI, R.; COSTA, R. G.; VASCONCELOS, V. R. Digestibilidade in vivo dos nutrientes de cultivares de amoreira (Morus alba L.) em caprinos. Ciência. Rural, Santa Maria, v. 34, n. 2, p. 539544, 2004.

ETHERIDGE, R. D.; PESTI, G. M.; FOSTER, E. H. A comparison of nitrogen values obtained utilizing the Kjeldahl nitrogen and Dumas combustion methodologies (Leco CNS 2000) on samples typical of an animal nutrition analytical laboratory. Animal Feed Science and Technology, Amsterdam, v. 73, n. 1, p. 21-28, 1998.

FERREIRA, D. F. Análises estatísticas por meio do Sisvar para Windows versão 4.0. In: REUNIÃO
ANUAL DA REGIÃO BRASILEIRA DA SOCIEDADE INTERNACIONAL DE BIOMETRIA, 45., 2000, São Carlos. Anais... São Carlos: UFSCar, 2000. p. 255-258.

FONSECA, A. S.; FONSECA, T. C. Cultura da amoreira e criação do bicho-da-seda. São Paulo: Nobel, 1986. 246 p.

HALL, M. B. Neutral detergent-soluble carbohydrates: nutritional relevance and analysis. Gainesville: University of Florida, 2000. 76 p.

KANDYLIS, K.; HADJIGEORGIOU, I.; HARIZANIS, P. The nutritive value of mulberry leaves (Morus alba) as a feed supplement for sheep. Tropical Animal Health and Production, Edinburgh, v. 41, n. 1, p.17-24, 2009.

LIU, J. X.; YAO, J.; YAN, B.; YU, J. Q.; SHI, Z. Q. Effects of mulberry leaves to replace rapeseed meal on performance of sheep feeding on ammoniated rice straw diet. Small Ruminant Research, Amsterdam, v. 39, n. 2, p. 131-136, 2001.

MAKKAR, H. P. S.; SINGH, B.; NEGI, S. S. Relationship of rumen degradability with microbial colonizatin, cell wall constituents and tannin levels in some tree leaves. Animal Production, v. 49, n. 2, p. 299-303, 1989.

MILLER, D.; MCDONALD, D.; ASIEDU, F. H. The effect of mulberry leaf meal on the growth performance of weaner goats in Jamaica. CARDI Review, St. Augustine, n. 5, p. 5-11, 2005.

MORENO, G. M. B.; SILVA SOBRINHO, A. G.; LEÃO, A. G.; LOUREIRO, C. M. B.; PEREZ, H. L.; ROSSI, R. C. Desempenho, digestibilidade e balanço de nitrogênio em cordeiros alimentados com silagem de milho ou canade-açúcar e dois níveis de concentrado. Revista Brasileira de Zootecnia, Viçosa, v. 39, n. 4, p. 853-860, 2010 a.

MORENO, G. M. B.; SILVA SOBRINHO, A. G.; ROSSI, R. C.; PEREZ, H. L.; LEAO, A. G.; ZEOLA, N. M. B. L.; SOUSA JUNIOR, S. C. Desempenho e rendimentos de carcaça de cordeiros Ile de France desmamados com diferentes idades. Revista Brasileira de Saúde e Produção Animal, Salvador, v. 11, n. 4, p. 1105-1116, 2010 b.

NAGESWARA, R. S. B.; NAWAB, S.; OGRA, J. L.Tree leaves based pelleted feeds and their utilization in goats. Indian Journal of Animal Nutrition, New Delhi, v. 13, n. 3, p. 174-177, 1996.

NATIONAL RESEARCH COUNCIL - NRC. Nutrients requirements of sheep. Washington: National Academies Press, 2007. 362 p.

OKAMOTO, F.; CUNHA, E. A.; BUENO, M. S.; SILVA, M. A.; SANTOS, L. E.; RODRIGUES, A. A. Desempenho de borregas da raça Santa Inês alimentadas com cana-de-açúcar e ramas de amoreira. Boletim de 
Indústria Animal, Nova Odessa, v. 65, n. 1, p. 1-6, 2008.

SANCHEZ, M. D. Mulberry: an exceptional forage available almost worldwide. In: SANCHEZ, M. D. Mulberry for animal production. Roma: Food and Agriculture Organization (FAO) of United Nations, 2002. p. 271-289. (Anexo 1).

SCHMIDEK, A. Composição bromatológica $e$ degradabilidade em caprinos de cultivares de amoreira (Morus alba L.). 1999. (Trabalho de Graduação em Zootecnia) - Faculdade de Ciências Agrárias e Veterinária. Universidade Estadual Paulista, Jaboticabal.

SILVA, C. D. A. Valor nutricional de fenos em rações para cordeiros alimentados em comedouros privativos. 2006. Dissertação (Mestrado em Agronomia) - Faculdade de Ciências Agrárias. Universidade de Marília, Marília.

SILVA, D. J.; QUEIROZ, A. C. Análise de alimentos: métodos químicos e biológicos. 3. ed. Viçosa: UFV, 2002. 235 p.

SNIFFEN, C.; BEVERLY, R. W.; MOONEY, C. S.; ROE, M. B.; SKIDMORE, A. L. Nutrient requirement versus supply in dairy cow: strategies to account for variability. Journal of Dairy Science, Champaign, v. 76, n. 10, p. 3160-3178, 1993.
TAKAHASHI, R. Sericicultura: amoreira (Morus alba L.) bicho da seda (Bombyx mori L.). Jaboticabal: FCAV/ UNESP, 1988. 135 p.

VAN SOEST, P. J. Nutritional ecology of the ruminant. New York: Cornell University Press, 1994. 476 p.

VAN WYK, J. A.; BATH, G. F. The FAMACHA system for managing haemonchosis in sheep and goats by clinically identifying individual animals for treatment. Veterinary Research, v. 33, n. 5, p. 509-529, 2002.

VU, C. C.; VERSTEGEN, M. W. A.; HENDRIKS, W. H.; PHAM, K. C. The Nutritive value of mulberry leaves (Morus alba) and partial replacement of cotton seed in rations on the performance of growing vietnamese cattle. Asian Australian Journal of Animal Science, Seoul, v. 24, n. 9, p.1233-1242, 2011.

YAMAMOTO, S. M.; SILVA SOBRINHO, A. G.; VIDOTTI, R. M.; HOMEM JÚNIOR, A. C.; PINHEIRO, R. S. B.; BUZZULINI, C. Desempenho e digestibilidade dos nutrientes em cordeiros alimentados com dietas contendo silagem de resíduos de peixe. Revista Brasileira de Zootecnia, Viçosa, v. 36, n. 4, p.1131-1139, 2007. 